\title{
Self-expanding metal stents versus antrectomy for the palliative treatment of obstructive adenocarcinoma of the gastric antrum
}

\author{
Juan Octavio Alonso-Larraga, Julio César Alvaro-Villegas, Sergio Sobrino-Cossio, \\ Angélica Hernández-Guerrero, Guillermo de la Mora-Levy and Paola Figueroa-Barojas \\ Department of Gastrointestinal Endoscopy. Instituto Nacional de Cancerología México, D.F. México
}

\begin{abstract}
Background: gastric cancer patients are first diagnosed with an unresectable tumor in up to $40 \%$ of cases. Gastric outlet obstruction causes nausea, vomiting, dehydration and malnutrition. The aim of the study was to compare self-expanding metal stents to antrectomy and Roux-en Y gastrojejunostomy for palliation of obstructive adenocarcinoma of the gastric antrum.

Methods: retrospective study in patients with obstructing cancer of the gastric antrum. Patients were divided into two groups: group A, underwent endoscopic placement of self-expanding metal stents and group B underwent surgical treatment with antrectomy and Roux-en Y gastrojejunostomy. Collected data included: age, gender, performance status (Karnofsky's score), body mass index, histopathology, clinical stage (TNM classification), technical and clinical success of the procedure, time to oral intake, in-hospital stay, reintervention rate, and complications related to the treatment and survival.

Results: a total of 39 patients with gastric adenocarcinoma were included, 21 male and 18 female. Nineteen patients were assigned to group A and 20 patients to group B. There were no statistically significant differences between groups in regards to age, body mass index, Karnofsky's score and clinical stage. The technical and clinical success was similar for both groups. There was a statistically significant difference between groups favoring self-expanding metal stent in time to oral intake $(1 \pm 0$ vs. $4.9 \pm 0.6$ days, $p=0.0001)$ and in-hospital stay $(0.94 \pm 1.18$ vs. $7.8 \pm 7.7$ days, $p=0.0005)$. We did not find statistically significant differences with regards to long-term survival.

Conclusions: in patients with malignant gastric outlet obstruction due to gastric cancer, endoscopic palliation with self-expanding metal stents provide a shorter interval to oral intake, shorter inhospital stay and lower rate of complications.
\end{abstract}

Key words: Self-expanding metal stents. Antrectomy. Gastric cancer.

Received: 10-10-11.

Accepted: 19-12-11.

Correspondence: Juan Octavio Alonso-Larraga. Department of Gastrointestinal Endoscopy. Instituto Nacional de Cancerología. Av. San Fernando No. 22, Col. Sección XVI Delegación Tlalpan, CP 14080 México, D.F. e-mail: joctavioalonso@yahoo.com.mx
Alonso-Larraga JO, Alvaro J, Sobrino-Cossio S, Hernández-Guerrero A, de la Mora-Levy G, Figueroa-Barojas P. Self-expanding metal stents versus antrectomy for the palliative treatment of obstructive adenocarcinoma of the gastric antrum. Rev Esp Enferm Dig 2012; 104: 185-189.

\section{INTRODUCTION}

Gastric cancer patients present with an unresectable tumor in up to $40 \%$ of cases $(1,2)$. Gastric outlet obstruction (GOO) is a frequent complications and presents as nausea, vomiting, dehydration and eventually malnutrition. Most patients at this stage have a short life expectancy if left without treatment (3-5). Open gastrojejunostomy (OGJ) has been considered the preferred treatment for relieving malignant $\mathrm{GOO}$ with good results and adequate symptom relief in most cases. Early major complications of OGJ can be seen in $6 \%$ of patients and late complications in up to $17 \%$, and are similar to those of self-expanding metal stents (SEMS) (6\% for early and $18 \%$ for late complications) (6). However, OGJ has a higher overall mortality when compared to SEMS (29 vs. 17\%; p < 0.001) (7).

Patients with OGJ have delayed gastric emptying, which can decrease oral intake for up to 8 days (8). While laparoscopic gastrojejunostomy is less invasive, adequate gastrointestinal function can also be delayed for a similar period, with this approach (9). Gastric stents are less invasive than surgery, allow for shorter hospital stays and earlier oral intake (10). There are a number of studies that compare palliative endoscopy with surgical treatment; however, most of them include patients with malignant GOO secondary to a variety of malignancies, including gastric, duodenal and biliopancreatic tumors. The aim of the present study was to compare SEMS with antrectomy and Roux-en Y gastrojejunostomy (A-RYGJ) for palliation of obstructive adenocarcinoma of the gastric antrum. 


\section{METHODS}

Retrospective, comparative study of a series of consecutive cases with malignant GOO secondary to gastric adenocarcinoma between January 2005 and December 2010 treated at the Instituto Nacional de Cancerologia in Mexico City. Patients over 18 years of age with stage IV tumors (any T, any N, Metastasis) candidates for palliative surgical or endoscopic treatment who were followed-up until death, were included. Patients with GOO secondary to causes other than gastric cancer (duodenal, pancreatic, ampullary, gallbladder cancer or extrahepatic cholangiocarcinoma) and those who were lost to follow up were excluded. Patients were divided into two groups: group A received endoscopic placement of a SEMS if there was GOO with metastatic disease and group B underwent A-RYGJ. A-RYGJ was considered when patients had metastatic diseases and was impossible to place a SEMS. Collected data included: age, gender, histopathology, clinical stage (TNM classification), performance status (Karnofsky's score), in-hospital stay in days, re-intervention rate, complications, and survival. The technical and clinical success of both endoscopic and surgical procedures was recorded, as well as treatment failures. All placed SEMS were uncovered TTS wallstents $(22 \mathrm{~mm}$ in diameter and $9 \mathrm{~cm}$ in length) manufactured by Boston Scientific.

\section{Definitions}

Technical success: adequate position and deployment of the SEMS or performance of A-YRGJ with adequate patency (6). Clinical success: symptom relief with adequate oral intake (6). Complications: any adverse event related to treatment. Early complications: those that presented in the first 7 days after treatment (6). Late complications: those that presented after 7 days of treatment (6). Karnofsky's score: as described (11). Reintervention: any surgical or endoscopic treatment performed after the initial treatment with the objective of relieving persistent or recurrent symptoms. Survival: time elapsed between initial endoscopic or surgical treatment and death of the patient. Treatment failure: inability to maintain adequate oral intake or symptom relief.

\section{Statistical analysis}

Descriptive statistics were used. Nominal variables were analyzed using chi square or Fisher's exact test; for quantitative variables, the Student's t-test with a 95\% confidence interval and a significance level of 0.05 was used. Survival was compared with Kaplan-Meier curves.

\section{RESULTS}

There were a total of 113 patients with gastric tumors of which 94 were submitted to surgery and 19 to endoscopic
Table I. Staging of patients according to TNM system

\begin{tabular}{|c|c|c|c|c|}
\hline Patients & $T$ & $N$ & $M$ & Localization \\
\hline 1 & T3eus* & N3eus & M1teus* & $A P$ \\
\hline 2 & T4eus & N2eus & M1teus & $A$ \\
\hline 3 & T4eus & N2eus & M1teus & $A P$ \\
\hline 4 & T4eus & N2eus & M1teus & $A$ \\
\hline 5 & T3eus & N2eus & M1teus & $A P$ \\
\hline 6 & T4eus & N2eus & M1teus & $A P$ \\
\hline 7 & T3eus & N3eus & M1teus & $A P$ \\
\hline 8 & T4eus & N3eus & M1eus & $A P$ \\
\hline 9 & T4eus & N3eus & M1teus & $A$ \\
\hline 10 & T4eus & N2eus & M1teus & $A P$ \\
\hline 11 & T4eus & N2eus & M1teus & $A P$ \\
\hline 12 & T4eus & N3eus & M1teus & $A$ \\
\hline 13 & T3eus & N2eus & M1eus & $A P$ \\
\hline 14 & T3eus & N2eus & M1teus & $A$ \\
\hline 15 & T4eus & N2eus & M1teus & $A P$ \\
\hline 16 & T4eus & N3eus & M1teus & $A P$ \\
\hline 17 & T4eus & N3eus & M1teus & $A$ \\
\hline 18 & T4eus & N3eus & M1teus & $A P$ \\
\hline 19 & T4eus & N3eus & M1teus & $A P$ \\
\hline 20 & $\mathrm{~T} 4 \mathrm{p}$ & N3p & $M 1 p^{*}$ & $A P$ \\
\hline 21 & T3p & N3p & M1p & $A$ \\
\hline 22 & $T 4 p$ & N3p & M1p & $A P$ \\
\hline 23 & $\mathrm{~T} 4 \mathrm{p}$ & N3p & M1p & $A$ \\
\hline 24 & $\mathrm{~T} 4 \mathrm{p}$ & $\mathrm{N} 2 \mathrm{p}$ & M1p & $A P$ \\
\hline 25 & $\mathrm{~T} 4 \mathrm{p}$ & N3p & M1p & $A P$ \\
\hline 26 & T3p & N2p & M1p & $A P$ \\
\hline 27 & T43p & $N 2 p$ & M1p & $A$ \\
\hline 28 & $\mathrm{~T} 2 \mathrm{p}$ & N3p & M1p & $A$ \\
\hline 29 & $\mathrm{~T} 4 \mathrm{p}$ & N3p & M1p & $A P$ \\
\hline 30 & $\mathrm{~T} 4 \mathrm{p}$ & N3p & M1p & $A P$ \\
\hline 31 & $\mathrm{~T} 4 \mathrm{p}$ & N3p & M1p & $A$ \\
\hline 32 & $\mathrm{~T} 4 \mathrm{p}$ & N3p & M1p & $A P$ \\
\hline 33 & $\mathrm{~T} 4 \mathrm{p}$ & N3p & M1p & $A$ \\
\hline 34 & $\mathrm{~T} 4 \mathrm{p}$ & N3p & M1p & $A P$ \\
\hline 35 & $\mathrm{~T} 4 \mathrm{p}$ & N3p & M1p & $A P$ \\
\hline 36 & $\mathrm{~T} 4 \mathrm{p}$ & N3p & M1p & $A$ \\
\hline 37 & T3p & N3p & M1p & $A P$ \\
\hline 38 & T3p & N3p & M1p & $A P$ \\
\hline 39 & $\mathrm{~T} 4 \mathrm{p}$ & N3p & M1p & $A$ \\
\hline
\end{tabular}

eus: endoscopic ultrasound. teus: tomography and endoscopic ultrasound. p: pathologic analysis of surgical specimen. $\mathrm{N}$ : it was evaluated according to the number of lymph nodes with characteristics suggestive of metastases during the endoscopic ultrasound examination or the number of neoplastic lymph nodes found in the pathologic analysis of the surgical specimen. A: antrum. AP: antropyloric.

treatment. A total of 39 patients with gastric adenocarcinoma (Table I), 21 male and 18 female were included. As only patients with stage IV tumors were compared, 19 patients were assigned to group A (SEMS) and 20 of 94 operated patients to group B (A-YRGJ). Group A had 13 male and 6 female patients with a median age of 54.6 years (range: 47.8-61.4). The median Karnofsky's score was 80 (range: 80-90) and the TNM clinical stage was IV in all 
Table II. Palliative treatment with SEMS or A-RYGJ in GOO

\begin{tabular}{|c|c|c|c|}
\hline & $\begin{array}{l}\text { Group A } \\
\text { SEMS } \\
n=20\end{array}$ & $\begin{array}{l}\text { Group B } \\
\text { A-RYGJ } \\
n=19\end{array}$ & $\begin{array}{l}\text { Value } \\
p\end{array}$ \\
\hline Male & 8 & 13 & \\
\hline Female & 12 & 6 & \\
\hline Age (mean in years) & $55.4 \pm 9.9$ & $54.6 \pm 8.3$ & 0.86 \\
\hline Body mass index (BMl in $\mathrm{kg} / \mathrm{cm}^{2}$ ) & $20.63 \pm 3.20$ & $20.62 \pm 6.23$ & NS \\
\hline Karnofsky's score & $82.10 \pm 11.3$ & $84.5 \pm 8.8$ & 0.46 \\
\hline Duration of symptoms (months) & $4.2 \pm 2.86$ & $5.1 \pm 4.91$ & 0.5 \\
\hline Hemoglobin levels & $10.7 \pm 2.07$ & $9.6 \pm 3.46$ & 0.25 \\
\hline Serum albumin & $2.92 \pm 0.74$ & $2.55 \pm 0.80$ & 0.14 \\
\hline Clinical stage (TNM) IV & $100 \%$ & $100 \%$ & NS \\
\hline Technical success & $100 \%$ & $100 \%$ & NS \\
\hline Clinical success & $95 \%$ & $100 \%$ & NS \\
\hline Time to oral intake (days) & $4.9 \pm 0.6$ & $1.00 \pm 0$ & $0.0001 *$ \\
\hline Early complications & $10 \%$ & $10 \%$ & NS \\
\hline Late complications & $20 \%$ & $5 \%$ & NS \\
\hline In-hospital stay (days) & $7.8 \pm 7.7$ & $0.94 \pm 1.18$ & $0.0005^{*}$ \\
\hline Re-intervention & $20 \%$ & $10 \%$ & NS \\
\hline Survival (months) & $4.5 \pm 3.2$ & $3.7 \pm 2.55$ & 0.45 \\
\hline
\end{tabular}

SEMS: self-expanding metal stents. A-RYGJ: antrectomy and Roux en $Y$ gastrojejunostomy.GOO: gastric outlet obstruction.

patients. The main symptom was abdominal pain (48\%); vomiting was present in $37 \%$ and postprandial fullness in $15 \%$. The median time to diagnosis was 5.1 months (range: 3.26-6.93). Technical and clinical success was achieved in $100 \%$ of cases. On average, oral intake was started within the first day (range: 0.786-1.21 days) from stent deployment. There were three complications $(15 \%)$ after stent placement, two of them presented early: one patient with abdominal pain and one with distal stent migration treated by stent replacement within 24 hours of initial procedure. The third patient had stent occlusion at follow-up due to tumor in-growth and was treated with argon plasma coagulation. Overall survival for this group was 3.7 months. The mean in-hospital stay was 0.94 days (range: 0.16-3.56) per patient, nine patients $(47 \%)$ were hospitalized overnight for observation, seven $(37 \%)$ were discharged home after the procedure, and three $(16 \%)$ required a hospital stay of more than one day.

Group B included eight male and 12 female patients with a median age of 55.4 years (range: 48.8-62) and a median Karnofsky's score of 80 (range: 70-90), the TNM clinical stage was also IV for all patients. The main symptoms for this group were abdominal pain (45\%), vomiting (30\%) and postprandial fullness $(25 \%)$. The median time to diagnosis was 4.2 months (range: 2.33-6.09). A-YRGJ was technically successful in $100 \%$ of the cases with a $95 \%$ clinical success rate. Oral intake was started after a median of 4.9 days (range: 4.69-5.1). There were complications in 30\% of the cases, $10 \%$ were early ( 2 cases of pneumonia) and

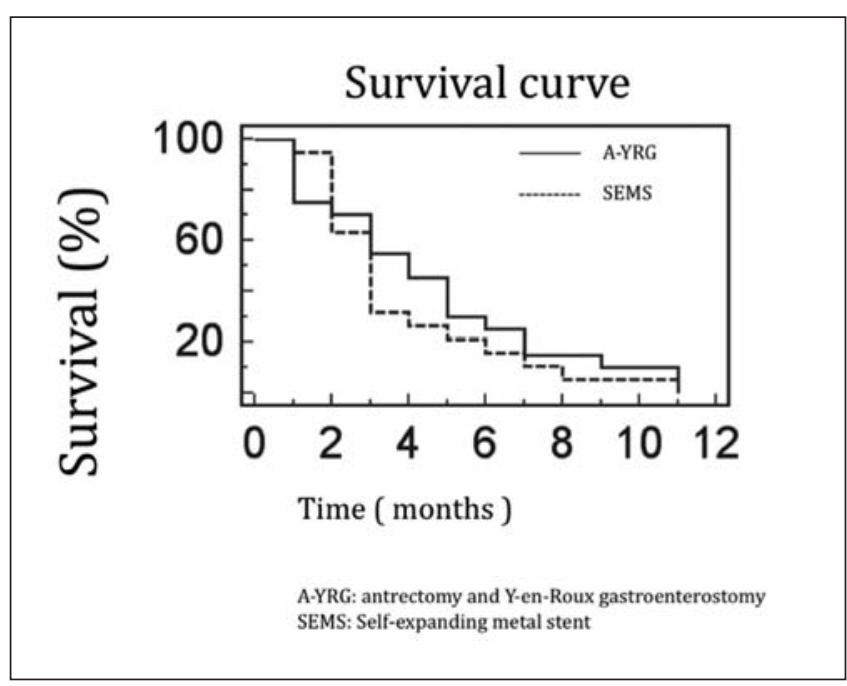

Fig. 1. Kaplan-Meir survival curve.

$20 \%$ were late (1 case of benign postsurgical stenosis of the gastrojejunostomy that presented 4 months after surgery, and 3 cases of obstruction for tumor recurrence at the anastomosis). The patient with stenosis of the gastrojejunostomy was managed by SEMS placement. The other three patients with cancer recurrence were treated by nasogastric tube to decompress the remnant stomach because of the short expected survival. The median survival in this group was 4.5 months (range 3.1-5.8) and the median in-hospital stay was 7.8 days (5.25-10.35).

There were no statistically significant differences between groups with regards to age, BMI, Karnofsky's score, hemoglobin level, albumin, duration of symptoms prior to treatment or survival. The technical and clinical success was similar for both groups (Table II). However, there was a statistically significant difference between groups favoring SEMS in time to oral intake $(1 \pm 0 v s$. $4.9 \pm 0.6$ days, $\mathrm{p}=0.0001)$ and hospital stay $(0.94 \pm 1.18$ vs. $7.8 \pm 7.7$ days, $\mathrm{p}=0.0005$ ). We did not find statistically significant differences between surgical and endoscopic treatment with regards to long-term survival (Table II, Fig. 1).

\section{DISCUSSION}

Several factors must be considered before deciding to perform either a surgical or endoscopic treatment for palliation of GOO. Most clinical trials do not distinguish between different causes of GOO (pancreatic, duodenal or gastric cancer), which is important when comparing endpoints, as highlighted in a study by Kim et al. (12). In this study, the authors reported a statistically significant difference in survival ( 153 vs. 90 days, $\mathrm{p}=0.041)$ after placement of a SEMS (partially covered Hercules SP stent, S\&G Biotech) in 207 patients with malignant GOO (147 due to 
gastric and 60 due to pancreatic cancer); survival was greater in patients with gastric cancer patients owing to a less aggressive biological behavior in comparison with pancreatic cancer.

The main objective of palliation in malignant gastric outlet obstruction is symptom control and restoration of oral intake. The choice of treatment depends on the expected survival for each patient.

When the expected survival is only a few days, the best choice is the placement of a nasojejunal feeding tube, while a gastrojejunostomy has been the standard of treatment for patients with a longer life expectancy.

When laparoscopic gastrojejunostomy and OGJ were compared, the results in terms of bleeding $(p=0.0001)$, shorter interval to oral intake $(\mathrm{p}=0.04)$ and shorter inhospital stay, favored laparoscopic gastrojejunostomy (13). However, when SEMS were compared with either laparoscopic or OGJ; the results in terms of time to oral intake (1-2.4 vs. 4-9 days) (6,14-17), in-hospital stay (2$7.1 v s .10-11.5$ days) $(6,15-18)$ and shorter procedure time (16) were statistically better for SEMS. As to morbidity and mortality many studies have reported that SEMS have more early complications $(p=0.004)$, shorter time to recurrence of obstructive symptoms $(\mathrm{p}=0.002)$, and to re-intervention $(p=0.004)(16,18)$. Also stents have proved to be less expensive than surgery $(15,19,20)$; have lower 30 day mortality (16.6 vs. 29.4\%) and complication rate (4 vs. $17.6 \%)$ and similar overall survival rate (1520 vs. 21.6-23 weeks) $(6,17)$ without statistically significant difference (20). It has also been reported that $83 \%$ of patients with SEMS alive after 30 days are able to eat solid foods (20). In the present study, the frequency of complications was lower for endoscopic treatment (15 vs. $30 \%$ ). Recurrent symptoms that require re-intervention have been reported in 13 to $18 \%$ of SEMS vs. $1 \%$ of OGJ $(6,21)$. Longer survival and probability of prostheses occlusion (tumor in-growth or overgrowth ) or gastrojejunostomy occlusion due to tumor recurrence at the anastomotic site, are directly related. Derivative surgical procedures carry a greater chance of occlusion due to tumor growth towards gastrojejunostomy site. However in our patients the re-intervention rate was higher in the surgical group, probably because of tumoral recurrence secondary to the advanced stage of the disease. It should also be considered that some patients will have persistent obstructive symptoms even after SEMS placement $(8 \%)$ or OGJ (9\%), which reflects the advanced stage in which they present (mesenteric involvement and carcinomatosis) (6). This can explain the similar rates of long-term obstruction in patients treated with SEMS and gastrojejunostomy. It is clear that in patients with stage IV gastric cancer, the benefits of endoscopic or surgical treatment are similar. However, surgery posses a greater risk for complications, longer in-hospital stay and longer time to oral intake after the procedure. Although the disadvantages of our study are that this it is retrospective, non-randomized and not directly comparative to laparoscopic techniques, as well as the lack of data about the presence of pain or quality of life; it has the advantages of including patients in both groups with similar age, duration of symptoms, same etiology and clinical stage. Also we did not compare SEMS with A-RYGJ. Finally, we have to admit that we still need clinical trials including other types of SEMS and laparoscopic techniques.

\section{CONCLUSION}

In patients with malignant GOO due to gastric cancer, endoscopic palliation with SEMS can provide a shorter interval to oral intake, shorter in hospital stay and lower rate of complications compared to A-RYGJ, with similar overall survival rate.

\section{REFERENCES}

1. Mauro MA, Koehler RE, Baron TH. Advances in gastrointestinal interventions: The treatment of gastroduodenal and colorectal obstructions with metallic stent. Radiology 2000;215:659-69.

2. Kaw M, Singh S, Gagneja H, Azad P. Role of self-expandable metal stents in the palliation of malignant duodenal obstruction. Surg Endosc 2003; 17:646-50.

3. Lopera JE, Brazzini A, Gonzales A, Castaneda-Zuniga WR. Gastroduodenal stent placement: current status. Radiographics 2004;24: 1561-73.

4. Wong YT, Brams DM, Munson L, Sanders L, Heiss F, Chase M, et al. Gastric outlet obstructions secondary to pancreatic cancer: surgical vs endoscopic palliation. Surg Endosc 2002;16:310-2.

5. Del Piano M, Ballare M, Montino F, Todesco A, Orsello M, Magnani C, et al. Endoscopy or sugery for malignant GI outlet obstruction? Gastrointest Endosc 2005;61:421-6.

6. Jeurnink SM, Van Eijck CH, Steyerberg EW, Kuipers EJ, Siersema PD. Stent versus gastrojejunostomy for the palliation of gastric outlet obstruction: a systematic review. BMC Gastroenterol 2007;7:1-10.

7. Espinel J, Vivas S, Munoz F, Jorquera F, Olcoz JL. Palliative treatment of malignant obstruction of gastric outlet using an endoscopically placed enteral wallstent. Dig Dis Sci 2001;46:2322-4.

8. Van Heek NT, De Castro SM, Van Eijck CH, Van Geenen RC, Hesselink EJ, Breslau PJ, et al. The Need for a prophylactic gastrojejunostomy for unresectable periampullary cancer: a prospective randomized multicenter trial with special focus on assessment of quality of life. Ann Surg 2003;238:894-902.

9. Nagy A, Brosseu KD, Hemming A, Scudamore C, Mamazza J. Laparoscopic gastroenterostomy for duodenal obstruction. Am J Surg 1995; 169:539-42.

10. Baron TH, Schofl R, Puespoek A, Sakai Y. Expandable metal stent placement for gastric outlet obstruction. Endoscopy 2001;33:623-8.

11. Schag CC, Heinrich RL, Ganz PA. Karnofsky performance status revisited: Reliability, validity, and guidelines. J Clin Oncology 1984;2:187-93.

12. Kim JH, Song HY, Shin JH, Hu HT, Lee SK, Jung HY, et al. Metallic stent placement in the palliative treatment of malignant gastric outlet obstructions: primary gastric carcinoma vs. pancreatic carcinoma. AJR 2009;193:241-7.

13. Navarra G, Musolino A, Venneri A, De Marco ML, Bartolotta M. Palliative antecolic isoperistaltic gastrojejunostomy: a randomized controlled trial comparing open and laparoscopic approaches. Surg Endosc 2006;20:1831-4.

14. Maetani I, Tada T, Ukita T, Inoue H, Sakai Y, Nagao J. Comparison of duodenal stent placement with surgical gastrojejunostomy for palliation in patients with duodenal obstructions caused by pancreatobiliary malignancies. Endoscopy 2004;36:73-8.

15. Mittal A, Windsor J, Woodfield J, Casey P, Lane M. Matched study of three methods for palliation of malignant pyloroduodenal obstruction. Br J Surg 2004;91:205-9. 
16. Fiori E, Lamazza A, Volpino P, Burza A, Paparelli C, Cavallaro G, et al. Palliative management of malignant antro-pyloric strictures. Gastroenterostomy vs endoscopic stenting. A randomized prospective trial. Anticancer Res 2004;24:269-71.

17. Espinel J. Sanz O, Vivas S, Jorquera F, Muñoz F, Olcoz JL, et al. Malignant gastrointestinal obstruction: endoscopic stenting versus surgical palliation. Surg Endosc 2006;20:1083-7.

18. Metha S, Hindmarsh S, Cheong E, Cockburn J, Saada J, Tighe R, et al. Prospective Randomized trial of laparoscopic gastrojejunostomy versus duodenal stenting for malignant gastric outflow obstruction. Surg Endosc 2006;20:239-42.
19. Yim HB, Jacobson BC, Saltzman JR, Johannes RS, Bounds BC, Lee $\mathrm{JH}$, et al. Clinical outcome of the use of enteral stents for palliation of patients with malignant upper GI obstruction. Gastrointest Endosc 2001;53:329-32.

20. Johnsson E, Thune A, Liedman B. Palliation of malignant gastroduodenal obstruction with open surgical bypass or endoscopic stenting: clinical outcome and health economic evaluation. World J Surg 2004;28:812-7.

21. García-Cano J, Sánchez-Manjavacas N, Viñuelas Chicano M, Jimeno Ayllón C, Martínez Fernández R, Gómez Ruiz CJ, et al. Palliative management of malignant gastric outlet obstruction with endoscopically inserted self-expanding. Rev Esp Enferm Dig 2008;100:320-6. 